\title{
Comparative Bond Efficiency of Deformed Concrete Reinforcing Bars
}

\author{
By Arthur P. Clark*
}

\begin{abstract}
The purpose of the tests was to determine the resistance to slip in concrete of 17 different designs of deformed reinforcing bars.

The tests were of the pull-out type in which the bars were cast in a horizontal position; the depth of concrete under the bars and the length of embedment were varied. The slip of the bar was measured at the loaded and free ends.

Three tests were made of each variable for each design of deformation.

It was established that a certain group of the bars was definitely superior to the others, in the sense that their average rating was significantly higher than the average of the others. Bars cast in the top position were much less effective than those cast in the bottom position.
\end{abstract}

\section{Introduction}

The tests of pull-out specimens reported herein constitute the first phase of a comprehensive investigation on the bond efficiency of deformed concrete reinforcing bars. The investigation was

${ }^{*}$ Research Associate at the National Bureau of Standards, representing the American Iron \& Steel Institute. initiated by the Committee on Reinforced Concrete Research of the American Iron and Steel Institute, and was conducted through the medium of a Research Fellowship established at the National Bureau of Standards in Washington.

\section{Materials}

\section{Reinforcing Bars}

The bars, all nominally $7 / 8$ in. in diameter, are illustrated in figures 1 and 2 by two views of each bar to show the pattern of the deformations as produced by the upper and lower rolls and also the relation of the two.

Diameters and areas were determined from the length and weight measurements of the bars. The yield point was determined in a $100,000-\mathrm{lb}-$ capacity testing machine of the beam and poise

\section{Contents}

I. Introduction

II. Materials__._._. 399

1. Reinforcing bars____._. 399

2. Concrete._._. 400

III. Description of test specimens_._._._._._. 401

IV. Testing procedure _._. 401

V. Results and discussions_._._._._._._._. 402

VI. Summary _. 
type by observing the drop of the beam. The height of the deformations was measured with a dial gage reading to $1 / 1000$ in. The bar was held in a jig (fig. 3), and readings were taken at three or more points around the bar at each of several positions along the length of the bar. A total of 92 measurements of deformation heights were made by three observers to determine the average heights of the deformations of each bar. The bearing area of the deformations per linear inch of bar was determined from the average height, projected length, and spacing. The two latter

TABLE 1.-Physical properties of deformed reinforcing bars

\begin{tabular}{|c|c|c|c|c|c|c|}
\hline \multirow{2}{*}{$\begin{array}{l}\text { Bar } \\
\text { No. }\end{array}$} & \multirow{2}{*}{$\begin{array}{l}\text { Area } 1 \\
\text { of bar }\end{array}$} & \multicolumn{2}{|c|}{ Deformations } & \multirow{2}{*}{$\begin{array}{l}\text { Yield } \\
\text { point }\end{array}$} & \multirow{2}{*}{$\begin{array}{l}\text { Tensile } \\
\text { strength }\end{array}$} & \multirow{2}{*}{$\begin{array}{l}\text { Elonga- } \\
\text { tion, in } \\
8 \text { in. }\end{array}$} \\
\hline & & $\begin{array}{l}\text { A verage } \\
\text { height }\end{array}$ & $\begin{array}{l}\text { Bearing } \\
\text { area }\end{array}$ & & & \\
\hline 1 & $\begin{array}{l}\text { in } .^{2} \\
0.61\end{array}$ & $\begin{array}{l}\text { in. } \\
0.045\end{array}$ & $\begin{array}{c}\text { in.2/in. } \\
0.082\end{array}$ & $\begin{array}{l}l b / \text { in }^{2} \\
44,100\end{array}$ & $\begin{array}{l}l b / i n .^{2} \\
77,700\end{array}$ & $\begin{array}{c}\text { Percent } \\
26.6\end{array}$ \\
\hline 2 & $\begin{array}{l}.01 \\
.58\end{array}$ & .046 & .149 & 43,200 & 74,100 & 33.6 \\
\hline 3 & .56 & .063 & .134 & 41,000 & 63,300 & 34.0 \\
\hline 4 & .59 & .067 & .192 & 37,500 & 58,900 & 25.8 \\
\hline 5 & .65 & .040 & .322 & 38,300 & 70,400 & 26.7 \\
\hline 6 & .60 & .055 & .354 & 43,900 & 81,100 & 21.9 \\
\hline 7 & .59 & .050 & .257 & 45,900 & 81,100 & 21.4 \\
\hline 8 & .61 & .055 & .390 & 53,300 & 77,800 & 25.4 \\
\hline 9 & .61 & .054 & .224 & 41,100 & 70,300 & 25.0 \\
\hline 10 & .60 & .050 & .332 & 43,100 & 71,000 & 25.4 \\
\hline 11 & .61 & .027 & .101 & 55,500 & 98,400 & 18.7 \\
\hline 12 & .60 & .028 & .100 & 61,000 & 103,100 & 19.5 \\
\hline 13 & .58 & .030 & .103 & 63,400 & 107,100 & 17.2 \\
\hline 14 & .59 & .067 & .102 & 46,900 & 81,100 & 20.3 \\
\hline 15 & .60 & .033 & .052 & 46,100 & 75,400 & 25.4 \\
\hline 16 & .59 & .033 & .041 & 35,750 & 56,000 & 36.7 \\
\hline 17 & .60 & $\ldots . .$. & $\ldots . . .$. & -....... & 128,700 & 11.3 \\
\hline
\end{tabular}

1 Areas, yield points, and tensile strengths therefrom are based on length and weight measurements in accordance with A.S.T.M. Designation A 15-39 All calculations of stresses in bars in pull-out specimens are based on nominal area $\left(0.60\right.$ in ${ }^{2}$.) of a $7 / 8$-in. plain round bar. dimensions were measured from an impression of the deformations projected on a plane surface made by rolling the bar in a thin layer of quicksetting plaster.

The physical properties of the bars are given in table 1 .

\section{Concrete}

Concrete was machine-mixed and proportioned by weight in the ratio of $1: 1.74: 2.23$. The watercement ratio was 5.75 gal per sack. Portland cement meeting the current standard specifications of the ASTM for type I cement was used.

The coarse aggregate was Potomac River gravel ranging in size from No. 4 to 1 in. The fine aggregate was Potomac River sand graded as shown in table 2. The dry rodded weight of the gravel was $106 \mathrm{lb} / \mathrm{ft}^{3}$ and the sand $109 \mathrm{lb} / \mathrm{ft}^{3}$.

\section{TABLE 2.-Sieve analysis of sand}

\begin{tabular}{|c|c|}
\hline $\begin{array}{c}\text { U. S. Stand- } \\
\text { ard Sieve } \\
\text { No. }\end{array}$ & $\begin{array}{c}\text { Percentage } \\
\text { passing by } \\
\text { weight }\end{array}$ \\
\hline & \\
4 & 98 \\
8 & 86 \\
16 & 71 \\
30 & 44 \\
50 & 12 \\
100 & 3 \\
\hline
\end{tabular}

The slump of the concrete averaged $4 \frac{1}{4} \mathrm{in}$. and the compressive strength of standard 6- by 12-in. cylinders, cured in moist air for 28 days, averaged $5,600 \mathrm{lb} / \mathrm{in}^{2}$. The modulus of elasticity at 37 days was $4,140,000 \mathrm{lb} / \mathrm{in}^{2}$.

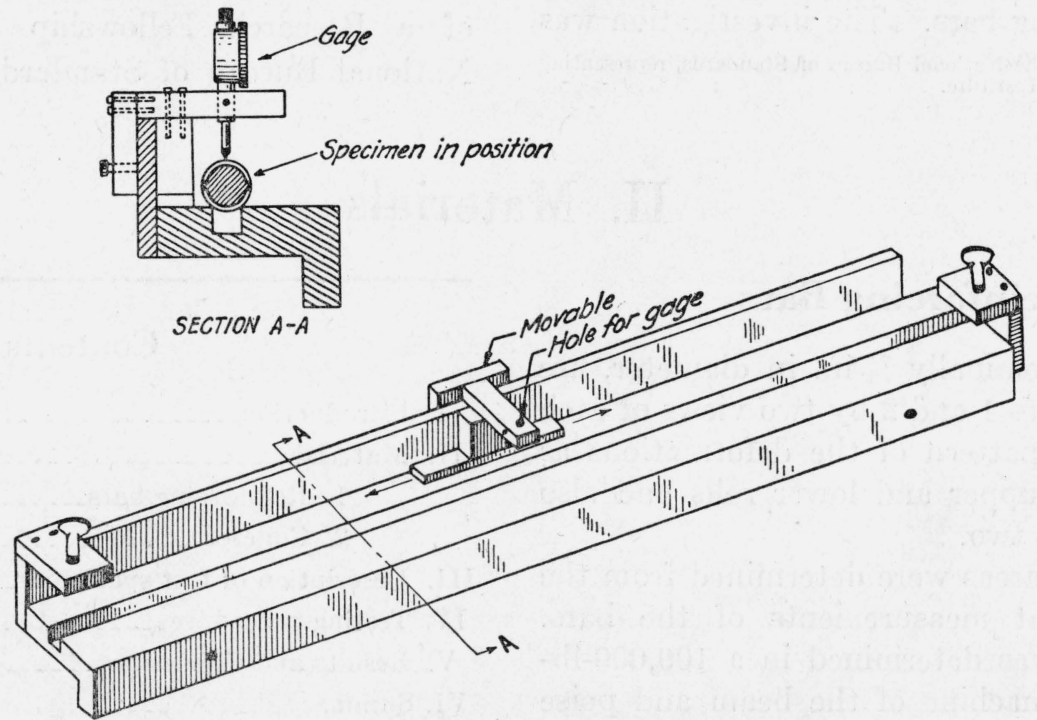

Figure 3.-Jig used in measuring height of deformations. 

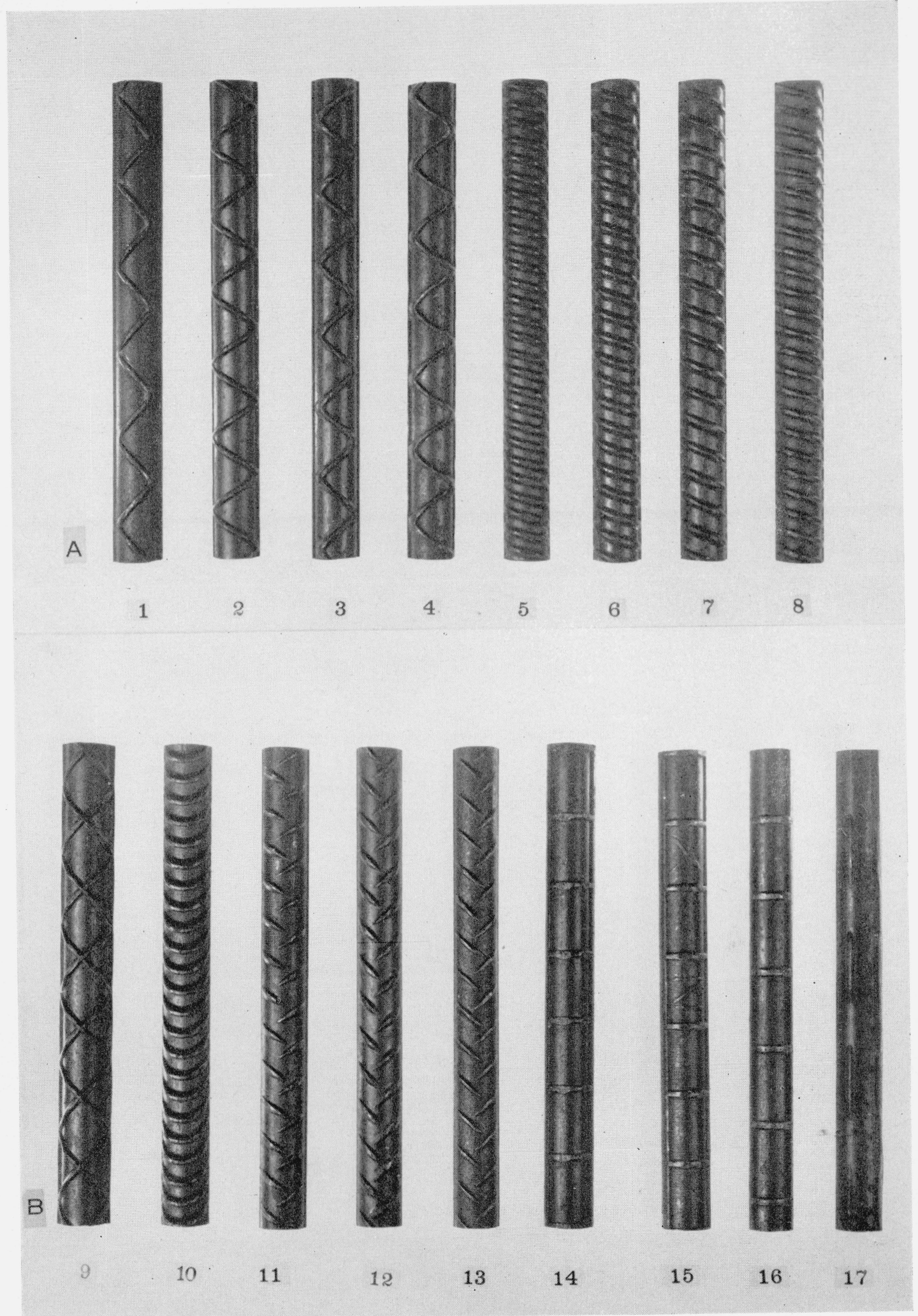

Figure 1.-Types of bars tested. 


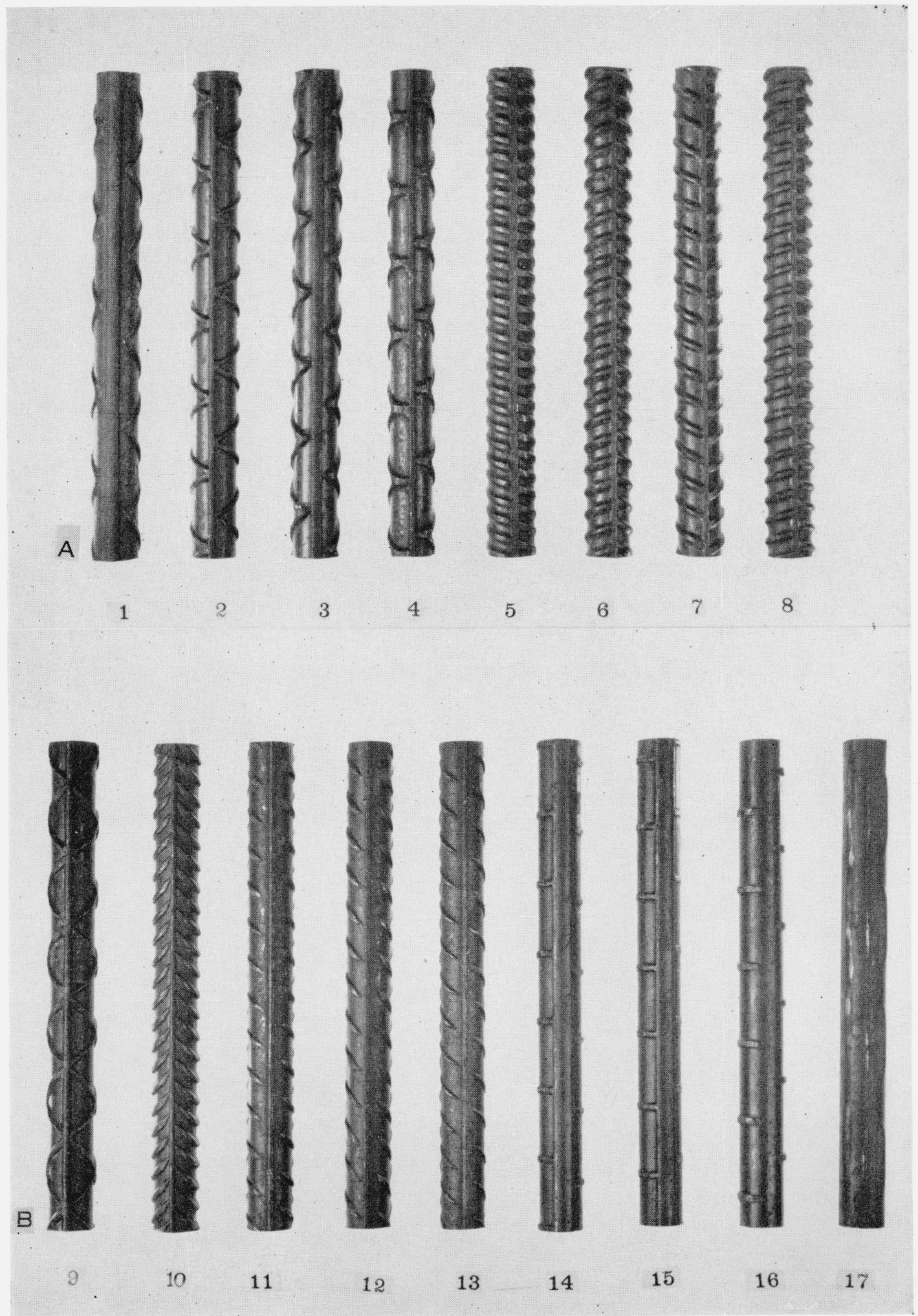

Figure 2.-Types of bars tested. 


\section{Description of Test Specimens}

The pull-out specimens were 8 by 9 in. in cross section and of two lengths, 8 in. and 16 in.; the bars in these specimens were held rigidly in the molds during casting with the longitudinal ribs in a horizontal plane. Two specimens were cast in a mold 18 in. in depth, with one bar near the top and one near the bottom; the depth of concrete

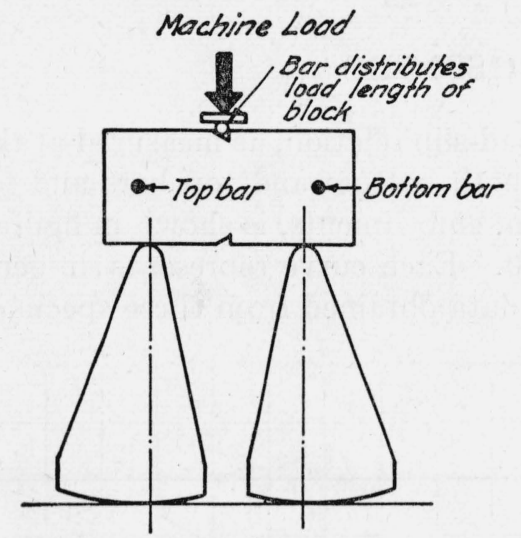

Figure 4.-Method of breaking blocks to produce two pullout specimens. under the bar in the top position was 15 in., and 2 in. for the bar in the bottom position. Triangular steel strips welded horizontally to the interior sides of the molds at midheight scored the concrete blocks to permit their subsequent separation into two specimens.

The molds were made of heavy steel sections fabricated to permit stripping of the specimens without damaging the concrete, and the molds were sealed prior to casting to prevent leakage. The concrete was deposited in the mold in three layers and rodded in place.

The blocks were kept in moist storage in the molds after casting, and at the end of 3 days were removed and divided into two specimens by loading as a beam in a testing machine, as illustrated in figure 4. All blocks broke in a plane where scored, and the surface departed from a plane surface generally only to about the extent of the size of the coarse aggregate particles. The average breaking load was $1,660 \mathrm{lb} / \mathrm{in}$. of length of specimen. The specimens were then placed in a moistroom until tested at the age of 29 to 31 days.

\section{Testing Procedure}

The pull-out specimens were tested in a 60,000lb-capacity fluid-support, Bourdon-tube hydraulic machine, and the load was applied at the rate of about $2,000 \mathrm{lb} / \mathrm{min}$, the dial gages being read without stopping the machine. The specimen was seated on a rubber cushion on two segments of a 2 -in. base plate attached to the face of a spherical bearing block (fig. 5). Slip of the bar was measured with 0.0001-in. micrometer dial gages and the readings were estimated to 0.00005 in. At the loaded end, two dials, Nos. 1 and 2, were held by a steel bar firmly attached to the bottom face of the specimen by bolts screwed into a series of nuts cast in the specimen. The dial gages were in contact with the smooth surface of a steel yoke fastened to the reinforcing bar by three setscrews with cupped ends 1 in. below the surface of the concrete. The support bar for the dial gages and the yoke were free to move in a recess in the base plate. As load was applied, the average of the two dial-gage readings indicated the amount of movement of the point on the reinforcing bar at which the yoke was attached with reference to the lower face of the concrete. To give

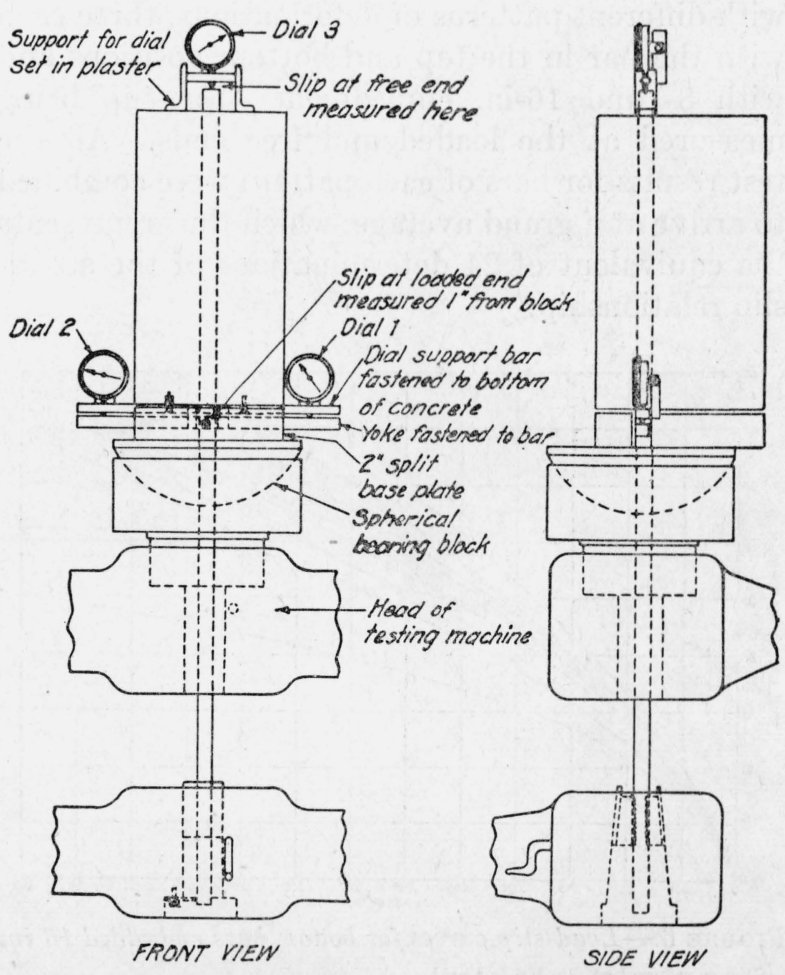

Figure 5.-Specimen in testing machine. 
the slip at the face of the concrete (slip at the loaded end), the dial-gage readings were corrected for the elongation of the reinforcing bar in the 1-in. distance between the point of attachment of the yoke and the face of the concrete.

The slip at the free end was read directly from the dial gage mounted on a support, seated in plaster on the top of the specimen with the point of the dial resting on the planed end of the bar.

Initial dial-gage readings were taken at a ma- chine load of $300 \mathrm{lb}$, then $600 \mathrm{lb}$, and readings at increments of $600 \mathrm{lb}$ were taken until the machine registered $7,200 \mathrm{lb}$, and then at increments of about $1,200 \mathrm{lb}$ until failure. The dial gages at the loaded end were removed as the stress in the bar approached the yield point or when a loosening of the support bar or yoke, due to the stretch in the bar or initial cracking of the concrete, made the readings of questionable value. Readings at the free end were continued until just before failure.

\section{Results and Discussions}

Tests in all cases were continued until failure of the specimen occurred, either by splitting of the concrete or by the bar pulling through the concrete. The typical splitting (79 percent of all specimens) was in a plane through the longitudinal ribs of the bar. The other specimens failed by splitting (13 percent) in a plane approximately at right angles to the plane through the longitudinal ribs. Seventeen specimens ( 8 percent) failed by the bar pulling through the concrete; these consisted of specimens containing bars No. 17 (with one exception), two each of Nos. 15 and 16, and one each of Nos. 11 and 13 .

Twelve tests were made with each of the 17 bars with different patterns of deformations, three each with the bar in the top and bottom positions and with 8- and 16-in. embedments, the slip being measured at the loaded and free ends. All the test results for bars of each pattern were combined to arrive at a grand average, which thus represents the equivalent of 24 determinations of the stressslip relationship.

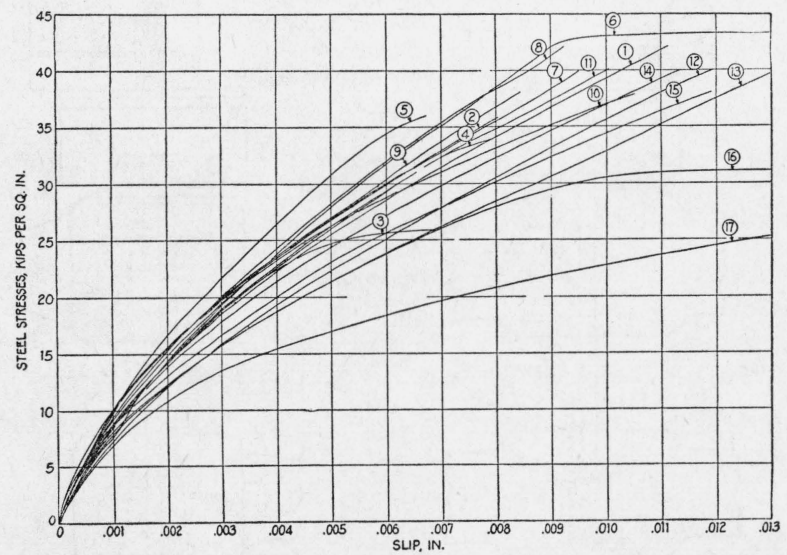

Figure 6.-Load-slip curves for bottom bars embedded $16 \mathrm{in}$. slip measured at the loaded end.
The load-slip relation, as measured at the loaded end for both bottom and top bars and for the 8and 16-in. embedments, is shown in figures $6,7,8$, 9 , and 10. Each curve represents, in general, the average data obtained from three specimens.

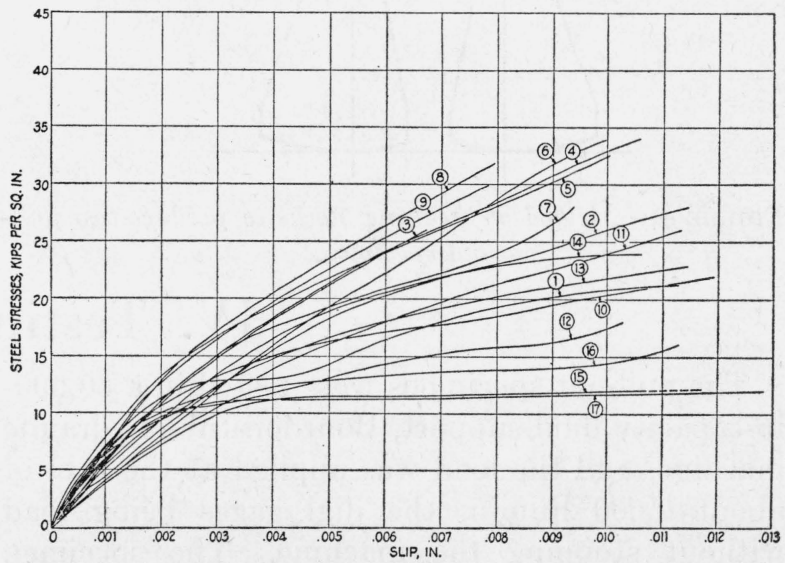

Figure 7.-Load-slip curves for top bars embedded 16 in. Slip measured at the loaded end.

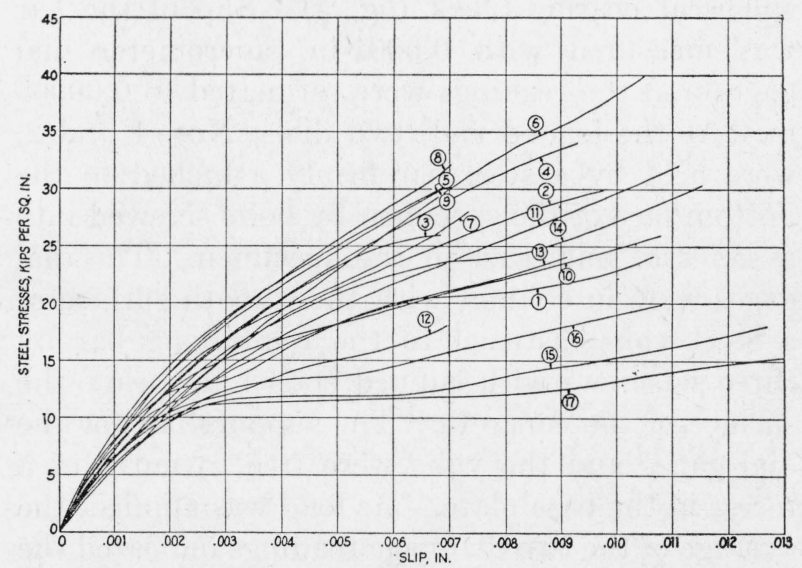

FIGURe 8.-Load-slip for the average of bottom and top bars embedded 16 in.

Slip measured at the loaded end. 


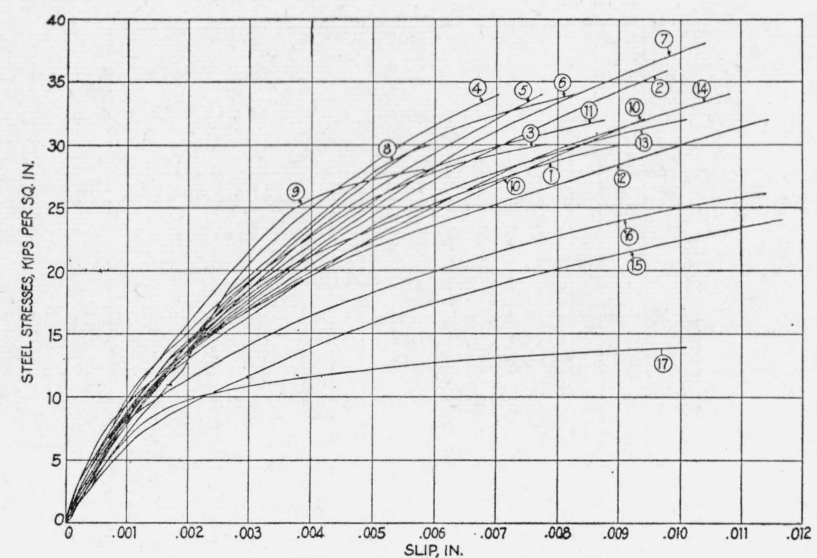

Figure 9.-Load-slip curves for bottom bars embedded 8 in. slip measured at the loaded end.

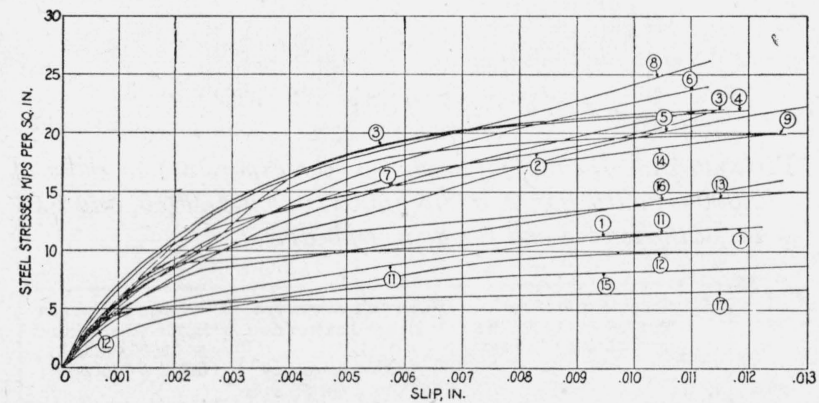

Figure 10.-Load-slip curves for top bars embedded 8 in. slip measured at the loaded end.

In the extensive literature dealing with the bond strength of reinforcing bars, the test bars have usually been rated by considering the stresses developed by the bars at some arbitrarily selected value of slip. In this investigation, an attempt was made to develop a method of rating bars that would take into account the stress-slip relationship for a considerable range of values of slip.

Load-slip curves of the bars of different designs show that some curves cross others. This means that one bar may have the highest stress for given slips along part of the curve, while the reverse may be true along another part of the curve.

Reinforced concrete has a wide variety of uses, ranging from members where the prime consideration is to keep cracks as narrow as possible, such as structures intended to confine liquids and avoid leakage or members exposed to attack by fumes or liquids that tend to hasten corrosion of steel, to those members where such conditions do not prevail and where deflection may not be a matter of particular concern. In the first case, a low value of design stress in the reinforcing steel is generally used, and in the other a high value. Between the extremes, other considerations may dictate the use of intermediate design stresses. A desirable concrete reinforcing bar would be one having a good bond resistance for all stresses within the range of probable use and up to the point of failure.

In this investigation, to determine the bars which could be expected to give the best bond resistance, it seemed logical to adopt a method for comparison that would rate the bars on the basis of average performance through a wide range of slip values. The method selected was to record the stress developed at several values of slip from the smallest at which readings were reliable up to the maximum slip developed by the majority of the bars. These stresses for each bar were totaled and the sum divided by the number of readings to obtain a figure indicative of the rating of the bar. These values may be used to indicate the bonding efficiency of the bars.

The values of slip at which the stresses were recorded are shown in table 3.

TABLE 3.-Values of slip at which stresses were recorded

\begin{tabular}{|c|c|c|c|}
\hline $\begin{array}{l}\text { Embed- } \\
\text { ment }\end{array}$ & $\begin{array}{c}\text { Position of } \\
\text { bar }\end{array}$ & Measured at- & Slip \\
\hline $\begin{array}{r}16 \\
16 \\
8 \\
8\end{array}$ & $\begin{array}{l}\text { Bottom } \\
\text { Top......... } \\
\text { Bottom } \\
\text { Top....... } \\
\text { Bottom } \\
\text { Top....... } \\
\text { Bottom } \\
\text { Top......... }\end{array}$ & 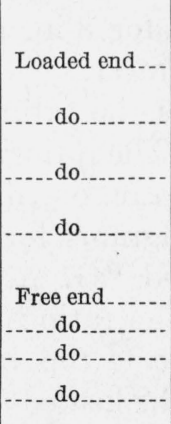 & 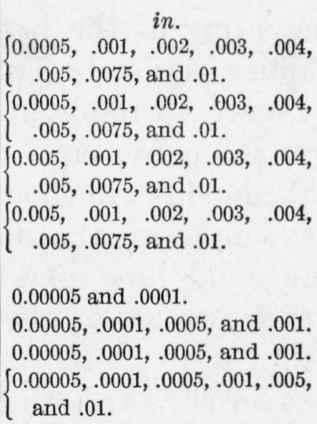 \\
\hline
\end{tabular}

The writer is of the opinion that this method, which is original insofar as he knows, is a reasonable one and gives a better basis for comparing bond performance than other methods heretofore employed.

The diagram in figure 11 represents, for slip at the loaded end, the rating of the bars for 16-in. embedment. The ordinates "steel stress" are the ratings used. In the vertical column for each type 


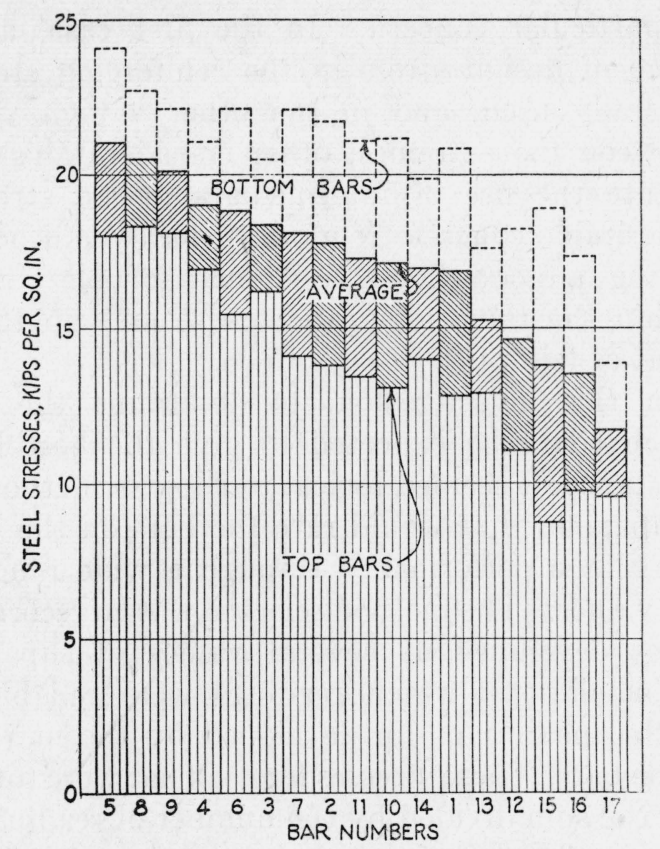

Figure 11.-Rating for each bar corresponding to slips of $0.0005,0.001,0.002,0.003,0.004,0.005,0.0075$, and 0.01 in. at the loaded end for 16-in. embedment.

of bar, the maximum height of the column indicates the rating of the bottom bars. The top of the vertical hatched portion indicates the rating for the top bars, and the top of the diagonal hatched portion indicates the average rating for both top and bottom bars.

Figure 12 represents for slip at the loaded end the rating of the bar for 8-in. embedment, in a manner similar to figure 11.

Figure 13 represents the rating of the bars for slips at the free end. The ratings for 8- and 16-in. embedments are shown on one diagram in a manner similar to the diagrams for the loaded end. The solid line marked "G. A." represents the grand average of all the ratings for 8-in. embedment, 16-in. embedment, top bars, and bottom bars for slips at both the loaded and the free ends.

In figures 11,12 , and 13 , the order in which the bars were arranged corresponds to the sequence of the average ratings of the bars with 16 -in. embedment. Bars 8, 9, 6, 3, 4, and 5 showed the highest grand-average ratings, and in the order named, the difference between the extreme values of the grand averages being only about 11 percent. The average of these six exceeds the average of the remaining bars by 31 percent.

Considering the slip at both ends and for both embedments, the rating for all bars in the top

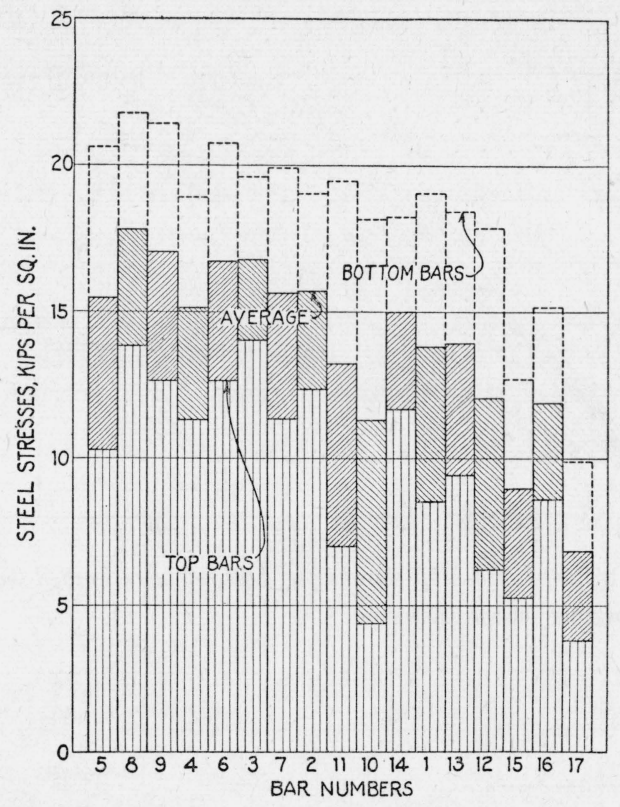

FiguRe 12.-Rating for each bar corresponding to slips of $0.0005,0.001,0.002,0.008,0.004,0.005,0.0075$, and 0.01 in. at the loaded end for 8-in. embedment.

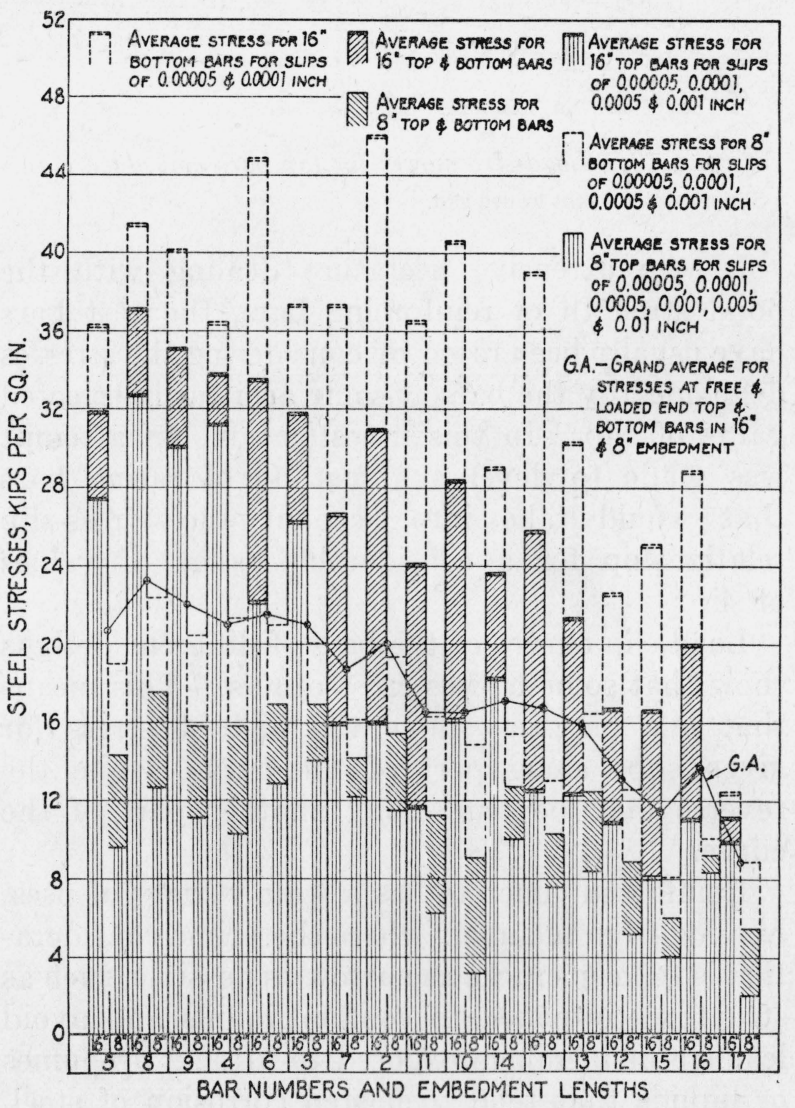

FIgure 13.-Rating for each bar corresponding to slips, as given in the notes, at the free end for 16-and 8-in. embedments. 
position was 56.8 percent of the rating for the bars in the bottom position. For bars 8, 9, 6, 3,4 , and 5 , this ratio was 67.9 percent.

For all bars of the same type of design, Nos. $5,6,7$, and 8 , the ratio of the rating of the top bars to that of the bottom bars was 62.9 percent, and for all bars of the same general type, Nos. 1, $2,3,4$, and 9 , this ratio was 61.8 percent. The data from these tests indicate that, for bars cast in a horizontal position, the pattern of the deformations on the bar has little influence on the loss of bond strength due to settlement of the plastic concrete under the bar.

Although a detailed statistical analysis of the dispersion of the data was not made, an examination of the ranges of values of stress for slips greater than 0.003 in. at the loaded ends of bars indicated that a difference of less than 10 percent between the ordinates of any two of the curves of figures $6,7,9$, and 10 is not positively significant. Similarly, differences of less than $1,500 \mathrm{lb}$./in. ${ }^{2}$ in the averages for the top and bottom bars shown in figures 11 and 12 or of less than $750 \mathrm{lb} . /$ in. $^{2}$ in the grand averages shown in figure 13 may not be significant.

Bond resistance is influenced by several factors, including the average height of the deformations, the bearing area of the deformations, the shearing area of the concrete between the deformations, the inclination of the bearing face of the deformations, and the angle the deformations make with the longitudinal axis of the bar. Although in this series of tests it was not possible to compare bars in which only one of these factors was a variable, the graphs in figure 14 show the relation of these factors to the grand-average stress developed in the bars. As was to be expected, the presence of other factors obscured, to some extent, the relation between the grand-average stress and the variables shown in figure 14; nevertheless, the graphs illustrate an unmistakable trend in all cases, except the graph for the shearing area.

It is apparent that, in general, the grandaverage stress increases with the bearing area of the deformations, their height, and the ratio of rating in the top bar to the rating in the bottom bar. It is of interest to note the similarity between the last two graphs named. The similarity of these graphs indicates that the height of deformations has an influence on the loss of bond strength due to the settlement of the plastic con- crete under the bars. The graph illustrating the effect of the ratio of shearing area to bearing area shows that the bars with low grand-average stresses have an excessively high shearing area, and for bars with high grand-average stresses, this ratio is substantially constant between the values of 6 and 11 .

The data from tests of bar No. 10 indicate that the inclination of the bearing face of the deformations is also a factor. Bar No. 10 has crescentshaped deformations, and these point in the same direction on both sides of the bar. One face of the deformation is substantially normal to the axis of the bar, whereas the opposite face is inclined at an average angle of less than 30 degrees with the axis of the bar. Tests were made with some specimens in which the bar was pulled with the crescents pointing in the direction of pull, and others were made in which the bar was pulled with the crescents pointing in the opposite direction. The bearing area, shearing area, height of deformation, and the distance the deformations

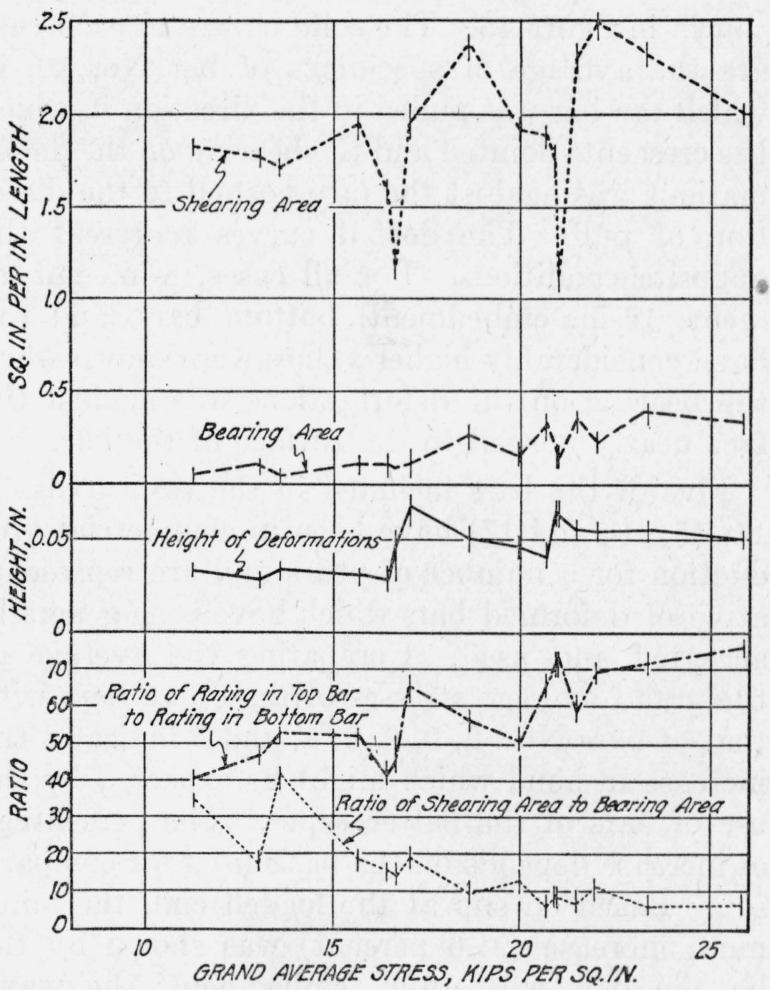

FIGURE 14.-Effect of height and bearing area of deformations and shearing area of concrete between deformations and the ratio of stress in top bars to the stress in bottom bars on the grand average stress in bars. 


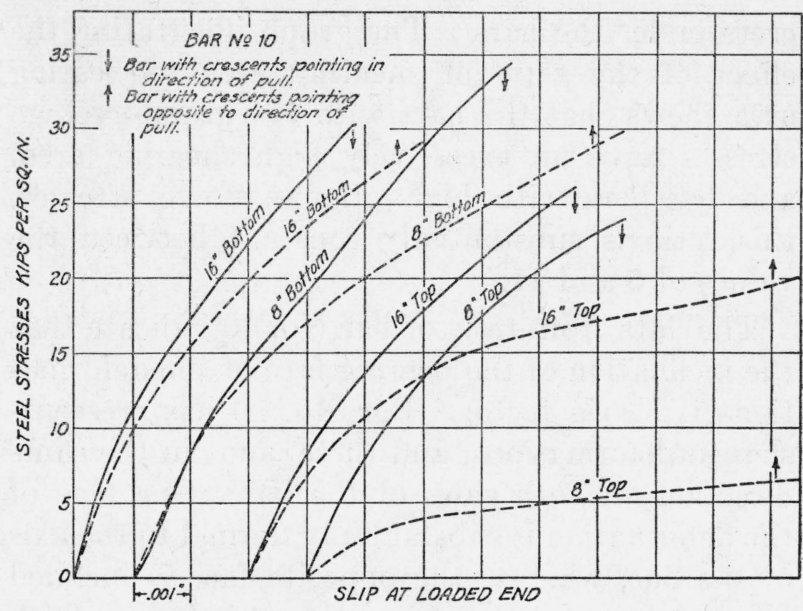

Figure 15.-Load-sïp curves for bar No. 10, determined for the loaded end.

extend around the bar were, of course, the same in all the tests of bar No. 10. Therefore, the only variable was the inclination of the face of the deformations and, to some extent, the shape of the concrete surface subjected to bearing stress. The load-slip relation for slip at the loaded end is shown in figure 15. The solid curves in each case are the average of specimens of bar No. 10, in which the bar was pulled in the direction in which the crescents pointed and the bearing on the deformations was against the face normal to the direction of pull. The dotted curves represent the opposite conditions. For all cases, 8-in. embedment, 16-in. embedment, bottom bars, and top bars, considerably higher values were shown when the bearing on the deformations was against the face nearly normal to the surface of the bar.

Five of the bars included in the tests (Nos. 1, $14,15,16$, and 17) have been in commercial production for a number of years and are representative of deformed bars which have been generally accepted and used. Comparing the average of the grand average stresses of these five bars with that of bars Nos. 8, 9, 6, 3, 4, and 5 indicates the increase in bond which might be expected by the use of bars of the better types. The percentage of increase depends on the basis used for comparison. Based on slip at the loaded end, the minimum increase (21.6 percent) was shown by the bottom bars with 16-in. embedment; the maximum (64.7 percent) by the top bars with 8 -in. embedment. The average increase of all bars at the loaded end was 39.8 percent. Based on slip

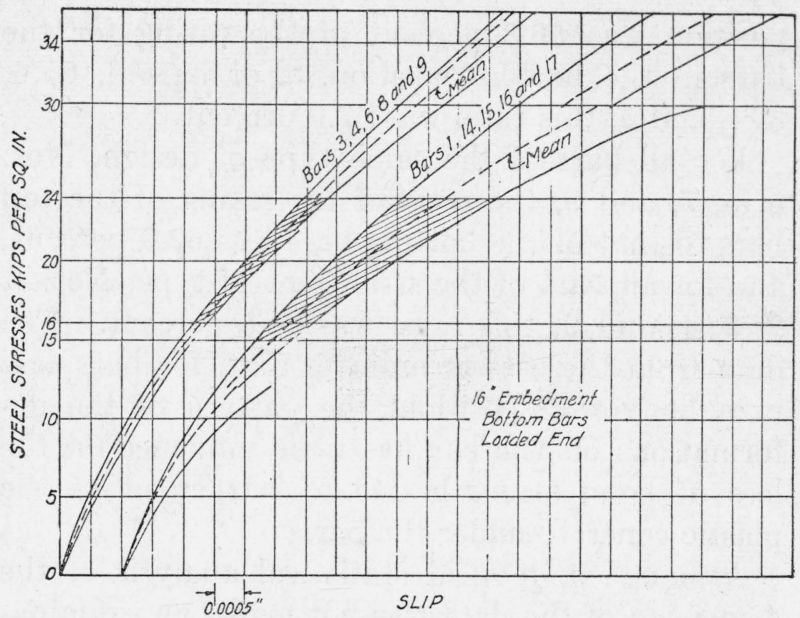

FIgURE 16.-Load-slip curves for the five commercial bars (Nos. 1, 14, 15, 16, and 17) and the five best bars (Nos. 3, 4, 6, 8, and 9) in bottom position embedded 16 in., determined for the loaded end.

at the free end, the minimum (47.1 percent) was shown by bottom bars with 16-in. embedment; the maximum (137.8 percent) by top bars with 16-in. embedment, and the average of all bars at the free end was 78.7 percent. The grand overall average increase was 60.1 percent.

The load-slip relation at the loaded end for the five bars with the highest ratings in this experiment and the group of five commercial bars cast in the bottom position for 16 -in. embedment is shown in figure 16 and for 8-in. embedment in figure 17. The range of usual design stresses $\left(16,000\right.$ to $24,000 \mathrm{lb} / \mathrm{in}^{2}$.) is indicated by the cross-

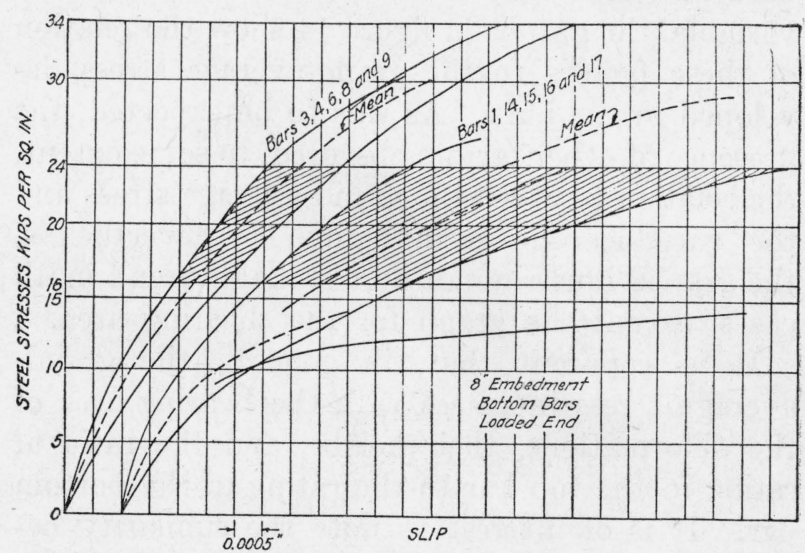

Figure 17.-Load-slip curves for the five commercial bars (Nos. 1, 14, 15, 16, and 17) and the five best bars (Nos. 3, 4, 6,8 , and 9) in bottom position embedded 8 in., determined for the loaded end. 
hatched portion. The five bars with the highest ratings show much less variation than the commercial bars.

The data for the two groups of bars presented in figures 16 and 17 represent the results obtained with bars tested in triplicate. In those cases where one specimen of a set of three failed prematurely either by splitting of the concrete or slipping of the bar, the data for that bar were discontinued at the maximum load representing all three specimens; these "breaks" occur in the lower enveloping curves where they are indicated by discontinuities in the curves. The upper enveloping curves also show "breaks" that are due to the fact that the load-slip curves of the several bars in a given group intersected each other.

\section{Summary}

The test specimens were of the pull-out type, in which the bars were cast in a horizontal position with length of embedment and depth of concrete under the bar varied. Provision was made for measuring the slip of the bar at both the loaded end and the free end of the bar.

The method used for evaluating the efficiency of the bars in bond resistance was based on the average performance for a range of slips as measured at the loaded end and at the free end for the bar with 2 in. and 15 in. of concrete under the bar and for 8-and 16-in. embedment.

The eight separate determinations for rating the bars gave, in general, consistent results. Considering the five bars rating highest in the grand average, one of the five rated highest in six of the determinations, one of the five rated second highest in all eight determinations, and one of the five rated third highest in all but one of the eight.

The average of the grand averages for bars Nos. $8,9,6,3,4$, and 5 was approximately 60 percent higher than for the five commercial bars.

Bars $8,9,6,3,4$, and 5 gave results which varied only about 11 percent from the highest. The five commercial bars gave results that varied by more than 41 percent from the highest.
In the top position, bars $8,9,6,3,4$, and 5 were about two-thirds as effective in bond as in the bottom position.

Height of deformations appears as an important factor in determining the effect of the settlement of the concrete under the bar. The pattern of the deformation does not seem to be an important factor in determining the bond resistance.

The inclination of the face of the deformations is an important factor in determining the bond resistance.

Attention is called to the fact that the conclusions arrived at herein do not necessarily apply when the conditions are different from those that prevailed in this investigation.

The outline and general procedure for this series was prepared by R. R. Zipprodt, research engineer for the Committee on Reinforced Concrete Research, and acknowledgment is made of the very willing cooperation of all members of the Bureau staff, and in particular that of D. E. Parsons, chief of the Division of Mineral Products, and David Watstein, Materials Engineer, for their helpfulness and continued interest.

Washington, May 6, 1946. 